\title{
Porcine coronary arteries: immunohistochemical profile of TNF-alpha, IL-1beta, TGF-beta1 and ICAM-1
}

\author{
S. Taurone ${ }^{1 *}$, M.T. Santarelli1*, E. De Santis ${ }^{2}$, C. Di Gioia ${ }^{3}$, E. Pompili², F. Pellegrino ${ }^{4}$, \\ P. Familiari ${ }^{5}$, V. Papa ${ }^{6}$, C. Zanza ${ }^{7,8,9}$, L. Coppola ${ }^{4}$, G. Familiari²*, M. Artico ${ }^{1 *}$ \\ ${ }^{1}$ Department of Sensory Organs, Sapienza University of Rome, Italy \\ ${ }^{2}$ Department of Anatomical, Histological, Forensic Medicine and Orthopaedics Sciences, Sapienza University of Rome, Italy \\ ${ }^{3}$ Department of Radiological, Oncological and Pathological Sciences, Sapienza University of Rome, Italy \\ ${ }^{4}$ UOC of Pathology, Sandro Pertini Hospital, Rome, Italy \\ ${ }^{5}$ Department of Human Neurosciences, Sapienza University of Rome, Italy \\ ${ }^{6}$ Department of Motor Sciences and Wellness, University of Naples "Parthenope", Naples, Italy \\ 'Department of Emergency Medicine, Foundation of Policlinico Agostino Gemelli-IRCCS, \\ Catholic University of Sacred Heart, Rome, Italy. \\ ${ }^{8}$ Department of Anaesthesia and Critical Care, AON SS Antonio e Biagio e Cesare Arrigo, Alessandria, Italy \\ ${ }^{9}$ Foundation Ospedale Alba-Bra and Department of Anaesthesia, Critical Care and Emergency Medicine, \\ Pietro and Michele Ferrero Hospital, Verduno, Italy
}

[Received: 5 June 2021; Accepted: 27 November 2021; Early publication date: 16 December 2021]

Background: In our study we used immunohistochemical technique to demonstrate the presence of the cytokines tumour necrosis factor alpha (TNF- $\alpha$ ), interleukin 1 beta (IL-1 $\beta$ ), transforming growth factor beta1 (TGF- $\beta 1$ ) and intercellular adhesion molecule-1 (ICAM-1) in porcine coronaries even in physiological conditions. Materials and methods: Inflammatory cytokines are polypeptide mediators which act as a communication signal between immune system cells and other types of cellsin different organs and tissues, both in human and pig coronary circulation. Results: Our results show that pro-inflammatory cytokines TNF- $\alpha$, IL-1 $\beta$, TGF- $\beta 1$ and ICAM-1 are also present in the medium tunica of the coronary arteries under physiological conditions. These results may be compared with those found in coronary atherosclerosis, where the increase in TNF- $\alpha$ has a dramatic effect on the function of the left ventricle, and the high value of IL-1 correlates directly with the extent of myocardial necrosis. In our study we observe the damage and activation of endothelial cells; this induces endothelial dysfunction by accumulation and oxidation of low density lipoproteins (LDL). The formation of oxidized $L D L$ could play a central role in the amplification of the inflammatory response causing an increased expression of pro-inflammatory cytokines which promotes leukocyte recruitment in the intimal layer. These leukocytes, after the adhesion to the endothelium, penetrate the intimate tunic.

Conclusions: Therefore inflammatory processes promote the onset and evolution of atheroma and the development of thrombotic complications. (Folia Morphol 2023; 82, 1: 119-126)

Key words: porcine coronary arteries, cytokines, IL-1 beta, TNF-alpha, TGF-beta1, ICAM-1

\footnotetext{
Address for correspondence: Dr. S. Taurone, Department of Sensory Organs, Sapienza University of Rome, Policlinico Umberto I, v. le del Policlinico 155, 00161 Rome, Italy, tel: +39 0649976852, e-mail: t.samanta@yahoo.it

*These authors equally contributed
}

This article is available in open access under Creative Common Attribution-Non-Commercial-No Derivatives 4.0 International (CC BY-NC-ND 4.0) license, allowing to download articles and share them with others as long as they credit the authors and the publisher, but without permission to change them in any way or use them commercially. 


\section{INTRODUCTION}

Cytokines are proteins produced by various types of cells in response to a stimulus; they have autocrine or paracrine effects and led the cells of the immune system to communicate with each other. Many cytokines are pleiotropic, because they act on a large variety of cells and tissues [5, 25]. Cytokines play an important role in cardiovascular disease by inducing inflammation, cell proliferation and apoptosis. Activated macrophages are known to be a major source of inflammatory cytokines. Previous studies have shown that cells present in the vascular wall, such as vascular smooth muscle and endothelial cells, produce different types of cytokines that are involved in cardiovascular disease $[16,18,27]$. Coronary atherosclerosis represents the main cardiac manifestation of a systemic pathological process initiated and fuelled by cellular and humoral mechanisms of an inflammatory nature [23]. Most cardiac pathologies such as acute myocardial infarction and its complications are the result of the action of a complex inflammatory network that culminates and is concentrated in the event acute but involves the entire body and in particular the cardio-vascular system [35]. The atherosclerotic process begins with the accumulation of low density lipoprotein (LDL)-cholesterol in the intestine with consequent endothelial damage, which favours inflammation, which is responsible for the expression of adhesion molecules on the cell membrane and the secretion of biologically active and chemotactic substances such as cytokines, growth factors and free radicals; these substances favour the recall and subsequent infiltration of leukocytes, with transformation of monocytes into macrophages. The secretion of inflammatory cytokines and some growth factors favour the proliferation and migration towards the intima of the smooth muscle cells (SMC) of the middle layer, promoting the formation of the fibrolipidic plaque $[2,43,44]$. The formation of atherosclerotic plaques determines the onset of coronary heart disease. They form on the inner walls of the cardiac arteries following the migration of SMC and the production of components of the extracellular matrix. These pro-inflammatory events recruit immune cells into the plaques causing severe inflammation and thrombosis [30]. The precise molecular mechanisms responsible for the transformation of an atheroma into an atherosclerotic plaque remain unknown, based on the theory that inflammation is the main trigger we decided to carry out a prelimi- nary study on porcine coronary arteries. The porcine heart offers really a good resemblance to the human heart, especially about coronary arteries and haemodynamics. Moreover, the wide social acceptance of their use, the similarity of their coronary circulation to that of humans, the approximation of their haemodynamic values and the size of the heart, make this animal model ideal for experimental studies [15, 20]. In the present study we studied the expression of some cytokines that are supposed to be involved in the cascade mechanisms after vascular damage.

Interleukin 1 (IL-1) and tumour necrosis factor alpha (TNF- $\alpha$ ) practically act on all cells and tissues and are defined as "primary inflammatory cytokines", because they are capable of setting in motion the entire cascade of mediators of the inflammatory response $[26,39]$. Transforming growth factor beta1 (TGF- $\beta 1$ ) is the most widespread cytokine present in endothelial cells, connective tissues and blood. Intercellular adhesion molecule-1 (ICAM-1) is a member of the immunoglobulin super family, including antibodies and T-cell receptors, it is present in low concentrations in the membranes of leukocytes and endothelial cells. ICAM-1 release may be induced by IL- 1 and TNF- $\alpha$ and it is expressed by vascular endothelium, macrophages and lymphocytes. Investigation of the mechanisms of atherosclerosis determined that inflammation plays a central role in the development, progression and outcome of acute coronary syndrome. Many scientific works demonstrate the role of some cytokines in acute coronary syndrome: IL-8, IL-10, IL-18, IL-2, TNF- $\alpha$, interferon $\gamma$ are involved in this clinical condition [26, 29, 31, 38, 39, 41, 42]. The inflammatory theory of Russell Ross [33] concerns the mechanism by which cardiovascular risk factors evoke a restorative response from the vascular wall. This mechanism consists of a response that begins by endothelial activation, a purely functional alteration, and then it progresses and stabilizes by the formation of an atherosclerotic plaque, a real morphological alteration. This key concept focuses scientific interest in the actors of the inflammatory response, in particular the leukocytes and the mediators that modulate and support this process. This theory is supported by experimental data and simultaneous elevation, in case of coronary atherosclerosis, of the markers of inflammation, including also some inflammatory cytokines with proven implications on prognosis. In various animal models of atherosclerosis, signs of inflammation have been found together with lipid 
accumulation in the wall of the arteries. In an experimental diabetic model obtained from pigs with streptozotocin-induced diabetes, an increased production of superoxide in coronary media and adventitia, due to increased nicotinamide-adenine dinucleotide phosphate (NADPH) oxidase activity, has been described [1]. Diabetes-induced oxidative stress resulted in an inflammatory response in the adventitia (increased expression of IL-6, TNF- $\alpha$, monocyte chemotactic protein-1, vascular cell adhesion molecule-1 (VCAM-1) and in the media tunic (VCAM-1 only). An enhanced redox state is accompanied by the upregulation of inflammatory cytokines (IL- 6 and TNF- $\alpha$ ), chemokines (monocyte chemoattractant protein-1 [MCP-1]), and adhesive molecules (VCAM-1). VCAM-1 and ICAM-1 are highly expressed around adventitial vasa vasorum. Expression of proinflammatory cytokines such as IL-6 and IL-8 has been reported to be increased in acute coronary syndromes [4, 37]. This observation suggests additional vascular portals for inflammatory cells. In fact, several inflammatory cells (lymphocytes and mast cells for instance) have been noted in the adventitia after fatal acute coronary syndromes or intractable vasospasm $[1,13]$. In our study we demonstrate the presence of cytokines TNF- $\alpha$, IL-1 $\beta$, TGF- $\beta 1$ and ICAM-1 in the porcine coronary arteries even in physiological conditions.

\section{MATERIALS AND METHODS}

\section{Sampling}

A total of 22 swine hearts (Sus scrofa domestica, Great white Polish pigs, all males, 18-30 weeks old, $80-140 \mathrm{~kg}$ of weight) were dissected up to 1 hour after commercial animal slaughter. No animals were sacrificed deliberately for this study and all samples were originally intended as obtained for use in the food industry. All hearts were normal with no congenital heart defects and were obtained from healthy animals that had no recognizable diseases. The hearts were obtained intact, washed until free of blood and blood clots using a saline solution. Specimens of coronary arteries (left carotid artery, left carotid right and circumflex coronary arteries) have been harvested, fixed in formalin, embedded in paraffin and then cut in serial sections ( $7 \mu \mathrm{m}$ of thickness).

\section{Immunohistochemistry (IHC)}

The immunohistochemical analysis was performed using the $A B C / H R P$ technique (avidincomplexed with biotinylated peroxidase) on $7 \mu \mathrm{m}$ thick paraffin sections that were cut using a rotative microtome. These sections were deparaffinised and hydrated through decreasing ethanol series to distilled water, then subjected to microwave irradiation and immersed in citrate buffer $(\mathrm{pH}=6)$ twice for 5 minutes each time. Subsequently, endogenous peroxidase activity was quenched using $0.3 \%$ hydrogenous peroxide in methanol for 30 minutes. To evaluate the immunolocalisation of TGF- $\beta 1$, IL- $1 \beta$, TNF- $\alpha$ and ICAM- 1 the following antibodies were employed: i) rabbit anti-TGF- $\beta 1$ polyclonal antibody (dilution 1:50; cat no. sc-130348; Santa Cruz, CA, USA); ii) rabbit anti-IL-1 $\beta$ polyclonal antibody (dilution 1:50; cat no. sc-12742; Santa Cruz Biotechnology, Santa Cruz, CA, USA); iii) mouse anti-TNF- $\alpha$ monoclonal antibody (dilution 1:100; cat no. sc-133192; Santa Cruz Biotechnology); iv) mouse anti-ICAM-1 monoclonal antibody (dilution 1:25; cat no. sc-107; Santa Cruz, CA, USA). Incubation with the primary antibodies was performed overnight at $4^{\circ} \mathrm{C}$. Optimal antibody dilution and incubation times were assessed in preliminary experiments. As negative control, the primary antibodies were omitted. After exposure to the primary antibodies all slides were rinsed twice in phosphate buffer $(\mathrm{pH}=7.4)$ and incubated for 1 hour with the appropriate secondary biotinylated antibody at the final dilution of 1:200. The secondary biotinylated antibodies against rabbit and mouse immunoglobulins were purchased from Abcam (biotinylated goat anti-mouse antibody and biotinylated goat anti-rabbit antibody). The slides were then incubated with peroxidase-conjugated avidin (Vector laboratories, Burlingame, CA, USA, Vectastain Elite $A B C$ kit Standard*PK 6-100) for 30 minutes. Slides were washed in phosphate buffer $(\mathrm{pH}=7.4)$ and treated with $0.05 \%$ 3,3-diaminobenzidine (DAB) and $0.1 \% \mathrm{H}_{2} \mathrm{O}_{2}$. Finally, sections were counterstained with Mayer's haematoxylin and dehydrated rapidly. The staining assessment was made by three experts. Negative control experiments were carried out: i) by omitting the primary antibody; ii) by substituting the primary antibody with an equivalent amount of non-specific immunoglobulins; iii) by pre-incubating the primary antibody with the specific blocking peptide (antigen/antibody $=5$ according to supplier's instructions). The staining assessment was made by two experienced observers in light microscopy. Immunoreactivity of TGF- $\beta 1$, IL- $1 \beta$, TNF- $\alpha$ and ICAM-1 was assessed in all samples.

The intensity of the immune reaction was assessed microdensitometrically using an IAS 2000 image anal- 

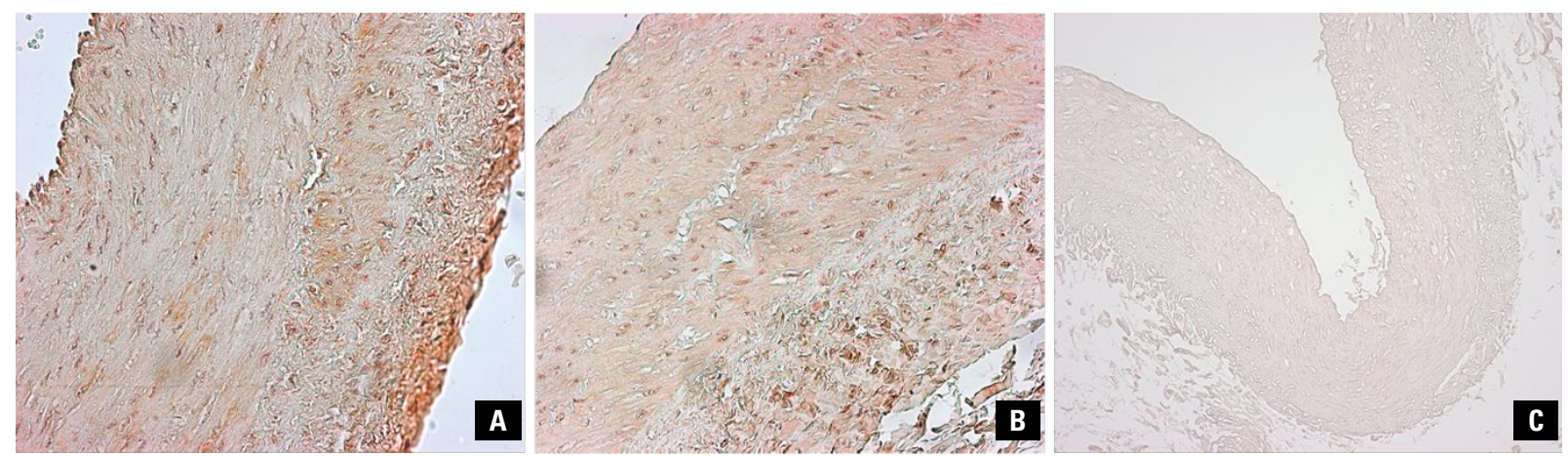

Figure 1. Immunohistochemical staining of porcine coronary arteries for interleukin $1 \beta$. A, B. Interleukin $1 \beta$ was observed in the endothelial cells and in the nuclei of the smooth muscle cells of the media. No adventitial inflammation was observed, we did not observe any significant neointima formation in all the samples examined; C. Negative controls, without antibody (A. $\times 20 ; B . \times 40 ; C . \times 10)$.
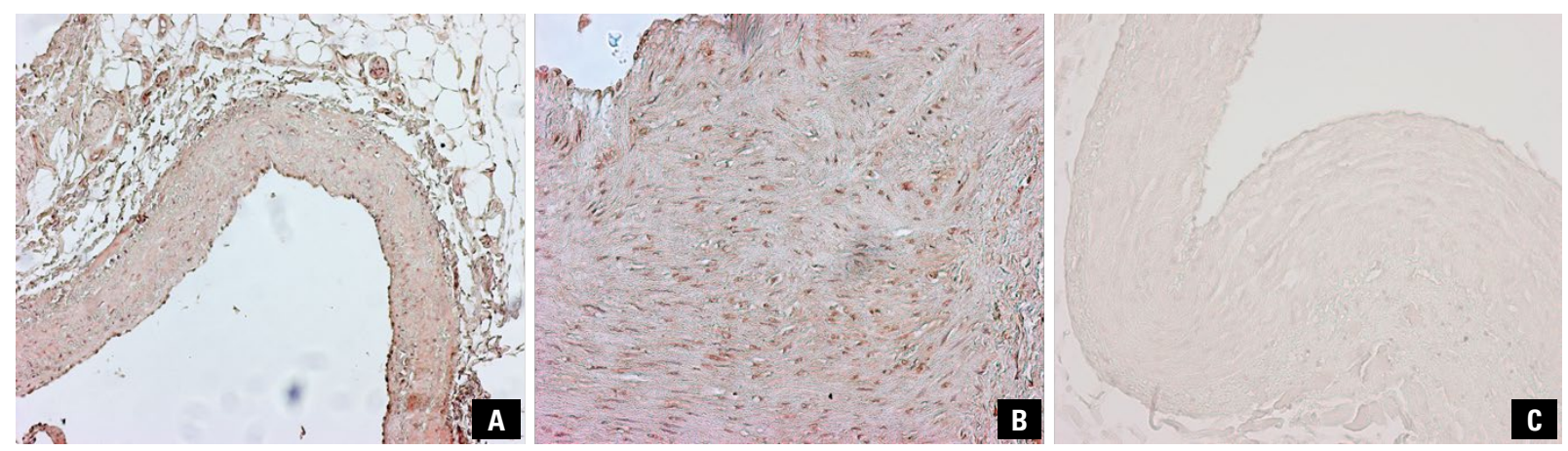

Figure 2. Immunohistochemical staining of porcine coronary arteries for transforming growth factor beta (TGF- $\beta 1$ ). Representative micrographs of vascular wall morphology are shown in panels A and B. TGF- $\beta 1$ shows positivity of the endothelium and of the nuclei of the smooth muscle cells of the media, we did not observe any significant neointima formation in all the samples examined; $\mathbf{C}$. Negative controls, without antibody (A. $\times 10 ;$ B. $\times 40 ;$ C. $\times 20)$.

yser (Delta Sistemi, Rome, Italy) connected via a TV camera to the microscope. Twelve $100 \mu \mathrm{m}^{2}$ areas were delineated in each section by measuring the diaphragm. The system was calibrated taking the background obtained in sections exposed to non-immune serum as zero.

\section{Statistical analysis}

All experiments were performed on at least three occasions in duplicate.

We divided the pigs into two groups: group $1-$ pigs 18-24 weeks old; group 2 - pigs 24-30 weeks old.

To perform the statistical analysis we compared the percentage of expression of each cytokine analysed in the two groups. Comparisons between the two groups were analysed using the unpaired Student's $t$ test. Quantitative data of the intensity of immune staining were analysed statistically by analysis of variance (ANOVA). Data are expressed as mean +
+ standard error of mean. A value of $p$-value $<0.05$ was considered significant.

\section{RESULTS}

On macroscopic examination, no obvious coronary lesions were found in the analysed segments. Positive areas for each immunohistochemical stain were measured. IL-1 $\beta$ protein was detected in the adventitial vessel endothelium in 12 of 12 specimens, IL-1 $\beta$ was present in macrophages (mainly foam cells) of 10 of 11 specimens of coronary arteries. Immunostaining for IL-1 $\beta$ showed a strong positivity in endothelial cells and in nuclei of the middle tunic SMCs (Fig. $1 A, B)$. The presence of IL-I $\beta$ in coronary arterial wall cells was studied by histochemistry to determine the reproducibility of the histological grading, 8 blocks had multiple sections cut. The other cytokines analysed, such as TGF- $\beta 1$, ICAM- 1 and TNF- $\alpha$, also showed positive reaction mainly in the nuclei of the SMCs of the media and in the endothelial cells (Figs. 2A; B, 

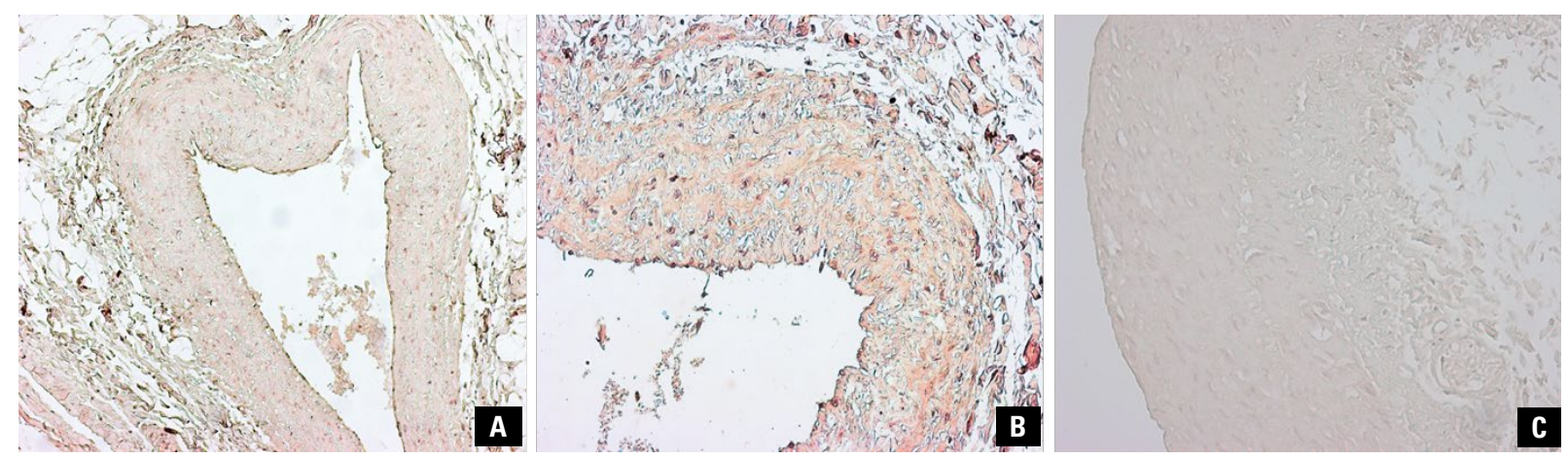

Figure 3. Immunohistochemical staining of porcine coronary arteries for intercellular adhesion molecule-1 (ICAM-1). A, B. ICAM-1 shows positivity in the endothelium and in the nuclei of smooth muscle cells of the media. No adventitial inflammation was observed; C. Negative controls, without antibody (A. $\times 10$; B. $\times 40$; C. $\times 40$ ).
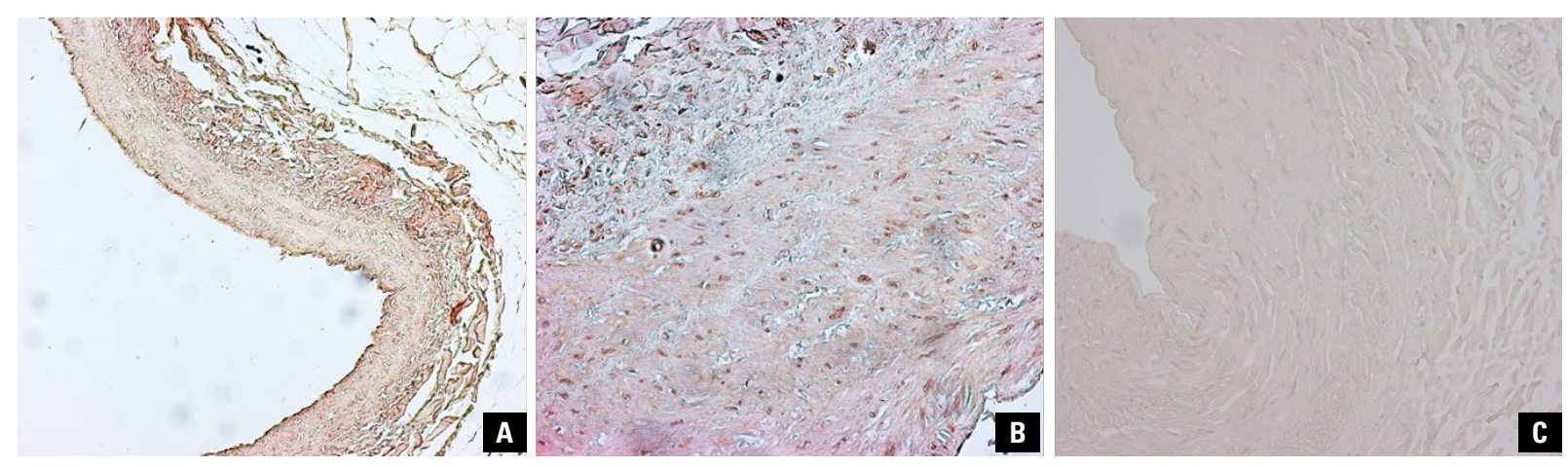

Figure 4. Immunohistochemical staining of porcine coronary arteries for tumour necrosis factor alpha (TNF- $\alpha$ ). Representative micrographs of vascular wall morphology are shown in panels $\mathbf{A}$ and $\mathbf{B}$. TNF- $\alpha$ was expressed weak positivity in some nuclei of the smooth muscle cells of the media; C. Negative controls, without antibody (A. $\times 10$; B. $\times 40$; C. $\times 40$ ).

$3 A, B ; 4 A, B)$. Our results show also that, under physiological conditions, the pro-inflammatory cytokines IL-1 $\beta$, TGF- $\beta 1$, ICAM- 1 and TNF- $\alpha$ are already present in the medium tunic of the coronary arteries. In our study high constitutive expression of TGF- $\beta$ is noted in coronary arteries, however, the in vivo relevance of this observation is unclear. Semi-quantitative analysis of inflammation was done by scoring the number of infiltrated inflammatory cells in sections of the vessel wall. In our study we observed that the typical morphology of the coronary arteries was preserved in the entire vessels analysed, in presence of inflammatory cytokines was observed a significant increase in neointimal thickness, neointimal area, the neointima was composed almost entirely of cells with little intercellular matrix.

Quantitative data of the intensity of immune staining, were analysed statistically. We have divided the pigs into two groups, In our analysis, there is no significant difference between the two groups. As shown in Table 1, the immunohistochemical analysis did not
Table 1. Expression levels (\%) of TGF- $\beta 1$, TNF- $\alpha$, ICAM-1, $\mathrm{IL}-1 \beta$ in coronary arterial wall of pigs, and respective levels of statistical significance (t-test)

\begin{tabular}{lccc}
\hline & $\begin{array}{c}\text { Group 1, pigs } \\
\text { 18-24 weeks old }\end{array}$ & $\begin{array}{c}\text { Group 2, pigs } \\
\text { 24-30 weeks old }\end{array}$ & P-value \\
\hline TGF- $\beta 1$ & $28.20 \pm 6.28$ & $29.10 \pm 4.15$ & 0.7098 \\
TNF- $\alpha$ & $31.70 \pm 6.24$ & $35.10 \pm 4.53$ & 0.1802 \\
ICAM-1 & $25.70 \pm 5.48$ & $28.00 \pm 4.19$ & 0.3057 \\
IL-1 $\beta$ & $34.70 \pm 4.50$ & $38.20 \pm 3.80$ & 0.0765 \\
\hline
\end{tabular}

The results were considered as statistically significant when $p$-value $<0.05$. TGF- $\beta 1$ - transforming growth factor beta1; TNF- $\alpha$ - tumour necrosis factor alpha; ICAM-1 intercellular adhesion molecule-1; LL-1 $1 \beta$-interleukin 1beta

reveal any significant differences in the expression of the cytokines analysed between the two groups.

\section{DISCUSSION AND CONCLUSIONS}

Cytokines play an important role in diseases of the cardiovascular system by inducing inflammation, cell proliferation and apoptosis. It is well known that activated macrophages are a major source of inflam- 
matory cytokines [13]. The intimal layer is the site of the earliest vascular atheromatous alterations. The pathogenetic development of these lesions is still not entirely clear today. It is believed that the endothelium plays a fundamental role in the early development of plaque. The most accredited hypothesis places a reaction to intimal layer damage at the basis of this process. In this case, atherosclerosis would represent an inflammatory response of the vascular wall. The location in the intimal layer of low density lipoproteins which, adhering to the proteoglycan layer [11] of this tunica, tend to form aggregates that are more difficult to remove from this site [8], represents a crucial phase of the inflammatory response. Their prolonged accumulation in the tunica intima exposes lipoproteins to the oxidative stress which later induces chemical modifications that are considered crucial for the progression of the atherosclerotic process [22]. Oxidized liporoteins are able to activate the local production of cytokines that stimulate the expression of adhesion molecules and growth factors from some of the endothelial cells. A functioning endothelium may resist to the adhesion and migration of circulating inflammatory cells. In atherosclerotic endothelial dysfunction, on the other hand, there is an increased expression of molecules such as VCAM-1, ICAM- 1 and selectins (E-selectin, P-selectin). It is noteworthy that VCAM-1 is a receptor for an integrin (VLA-4) which is selectively expressed on cells that are early found in the native atheroma as monocytes and T lymphocytes. VCAM-1 and ICAM-1 promote the adhesion and immobilisation of circulating cells [32], while the role of selectins (particularly P-selectin) is related to migration of leukocytes through the endothelial layer [21]. In addition to these adhesion molecules, some chemoattractive factors are important for the intimal migration of leukocytes adhered to the endothelium. Oxidized LDL and other factors expressed in the rising atheroma stimulate the production of MCP-1 which is a great activator of monocyte chemotaxis [12]. The inflammatory cells widely found in the newly formed atheroma are macrophages and T-lymphocytes. Once transformed into foamy cells due to cytoplasmic lipids accumulation, these macrophages are found more frequently in atheroma, where cytokines and growth factors are produced.

The first pathologically relevant atherosclerotic lesion, the so called "lipid streak", begins to form as foamy cells start to accumulate in the intimate layer. This process is still potentially reversible.
The foamy cells of the lipid streak acts as a promoter of the inflammatory process of the vascular wall, which synthesizes and releases cytokines, chemotactic factors and oxidizing radicals. This system of immune cells do not need antigenic stimuli to sustain itself [14]. TNF- $\alpha$, IL-2, IL-6, interferon- $\gamma$, and other pro-inflammatory factors are widely produced by Th1 subpopulation, while Th2 lymphocytes, among other secreted factors, synthesize and release IL-10, the main anti-inflammatory cytokine. The role of acquired immunity, and in particular the $T$ helper mediated one, could therefore orchestrate the inflammatory process triggered in the growing plaque. The cytotoxic T lymphocytes could mediate the release of lipolytic and proteolytic substances, oxidizing and inducing apoptosis of many cell types such as macrophages [36]. Activated SMCs are also capable of secreting factors structurally similar to TGF- $\beta$ and pro-calcifying molecules as well as calcium binding proteins. These molecules therefore, influence a common phenomenon in advanced atheromatous plaques: the mineralisation. In growing atheroma, SMCs are not the only non-immune cells to migrate and replicate, but even endothelial cells may localise in the plaque and, under the stimulation of molecules such as vascular-endothelial and fibroblast growth factor (VEGF and FGF), can also organize themselves to form microscopic neovascular plexuses rich in adhesion molecules that promote cell migration. These vascular structures also appear to be important for plaque progression, as demonstrated by the fact that anti-neoangiogenic factors can limit their development [10]. When plaque extends beyond remodelling positive capacity of the vessel involved, it begins to produce luminal stenosis, which progressively narrows the internal diameter of the artery and causes a reduction in blood flow. In the specific case of coronary arteries an imbalance between demand and request for oxygen in the myocardium, may lead to the development of a chronic ischaemic heart disease. Activated monocytes are capable of produce cytokines (such as TNF- $\alpha$ and IL-6) that maintain and amplify the inflammatory cascade. The transductive pathway mediated by the transcription factor nuclear factor $\kappa B(N F-K B)$ plays a fundamental role in progression of atherosclerosis, and its activation leads to an increase in production of the main pro-inflammatory cytokines, including IL-6 and TNF- $\alpha[9,24,28]$. In our study, we hypothesized that cytokines released by activated macrophages and cells localized in the vas- 
cular wall may play an important role in the formation of atherosclerotic lesions, triggering the upregulation of vasoactive substances and growth factors. In fact, previous studies $[3,19]$ have pointed out that the inflammatory cell infiltrate is more expressed during the early phases of atheromas growth, suggesting that inflammatory cytokines are responsible for the initiation of formation of the atherosclerotic lesions. Neoangiogenesis is a typical feature found in more advanced plaques. Angiogenesis is physiologically regulated by VEGF and its inhibitors. Hypoxia is the major stimulus for the production and cellular release of VEGF. In atherosclerotic lesions there is an expression of VEGF caused by hypoxia and release of molecules by macrophages. Small vessels then form inside the plaque and this phenomenon makes the plaque more unstable, thus facilitating the macrophage recall and a possible internal bleeding. VEGF is expressed by endothelial cells, macrophages and SMCs $[6,17]$. The presence of VEGF in the carotid plaque correlates with the presence of a newly formed vascular component, SMCs and inflammation cells $[17,40]$. The correlation between the presence of VEGF in the plaque and structural alterations (breaking of the fibrous cap), greater positivity to CD34 (endothelial marker) and expression of VEGFR1 in the present cells has been clearly demonstrated. The evaluation of blood levels of VEGF may be a useful tool to identify atherosclerotic lesions rich in microvessels and therefore more unstable $[7,34]$. Monitoring of elements related to the neoformation of atherosclerotic plaques is the primary objective of numerous new studies which take into consideration the serious consequences that could be caused by the presence of an atherosclerotic plaque in the carotid district, which really represents a high risk condition for the development of cerebrovascular events.

\section{Conflict of interest: None declared}

\section{REFERENCES}

1. Åkerblom A, James SK, Lakic TG, et al. Interleukin-18 in patients with acute coronary syndromes. Clin Cardiol. 2019; 42(12): 1202-1209, doi: 10.1002/clc.23274, indexed in Pubmed: 31596518.

2. Alexander $H$, Sprague R, Khalil A. Inflammatory cytokines in vascular dysfunction and vascular disease. Biochem Pharmacol. 2009; 78(6): 539-552, doi: 10.1016/j. bcp.2009.04.029, indexed in Pubmed: 19413999.

3. Alexander MR, Owens GK. Epigenetic control of smooth muscle cell differentiation and phenotypic switching in vascular development and disease. Annu Rev Physiol. 2012;
74: 13-40, doi: 10.1146/annurev-physiol-012110-142315, indexed in Pubmed: 22017177.

4. Apostolakis S, Vogiatzi K, Amanatidou V, et al. Interleukin 8 and cardiovascular disease. Cardiovasc Res. 2009; 84(3): 353-360, doi: 10.1093/cvr/cvp241, indexed in Pubmed: 19617600

5. Ballou S, Lozanski G. Induction of inflammatory cytokine release from cultured human monocytes by C-reactive protein. Cytokine. 1992; 4(5): 361-368, doi: 10.1016/10434666(92)90079-7.

6. Bianchi E, Artico M, Di Cristofano C, et al. Growth factors, their receptor expression and markers for proliferation of endothelial and neoplastic cells in human osteosarcoma. Int J Immunopathol Pharmacol. 2013; 26(3): 621-632, doi: 10.1177/039463201302600306, indexed in Pubmed: 24067459.

7. Bonomini $F$, Taurone $S$, Parnigotto $P$, et al. Role of parnaparin in atherosclerosis. Int J Exp Pathol. 2016; 97(6): 457-464, doi: 10.1111/iep.12217, indexed in Pubmed: 28205266.

8. Camejo G, Hurt-Camejo E, Wiklund O, et al. Association of apo B lipoproteins with arterial proteoglycans: pathological significance and molecular basis. Atherosclerosis. 1998; 139(2): 205-222, doi: 10.1016/s0021-9150(98)00107-5, indexed in Pubmed: 9712326.

9. De Bosscher K, Vanden Berghe W, Haegeman G. The interplay between the glucocorticoid receptor and nuclear factor-kappaB or activator protein-1: molecular mechanisms for gene repression. Endocr Rev. 2003; 24(4): 488-522, doi: 10.1210/er.2002-0006, indexed in Pubmed: 12920152.

10. Devaraj S, Kumaresan PR, Jialal I. Effect of C-reactive protein on chemokine expression in human aortic endothelial cells. J Mol Cell Cardiol. 2004; 36(3): 405-410, doi: 10.1016/j.yjmcc.2003.12.005, indexed in Pubmed: 15010279.

11. Ding Z, Pothineni NV, Goel A, et al. Impact of hepatitis C seropositivity on the risk of coronary heart disease events. Am J Cardiol. 2014; 114(12): 1841-1845, doi: 10.1016/j. amjcard.2014.09.020, indexed in Pubmed: 25438910.

12. Dong ZM, Chapman SM, Brown AA, et al. The combined role of $\mathrm{P}$ - and $\mathrm{E}$-selectins in atherosclerosis. J Clin Invest. 1998; 102(1): 145-152, doi: $10.1172 / \mathrm{JCl} 3001$, indexed in Pubmed: 9649568.

13. Gerdes N, Sukhova GK, Libby P, et al. Expression of interleukin (IL)-18 and functional IL-18 receptor on human vascular endothelial cells, smooth muscle cells, and macrophages: implications for atherogenesis. J Exp Med. 2002; 195(2): 245-257, doi: 10.1084/jem.20011022, indexed in Pubmed: 11805151.

14. Gu L, Okada Y, Clinton S, et al. Absence of monocyte chemoattractant protein-1 reduces atherosclerosis in low density lipoprotein receptor-deficient mice. Mol Cell. 1998; 2(2): 275-281, doi: 10.1016/s1097-2765(00)80139-2.

15. Hołda MK, Hołda J, Koziej M, et al. Porcine heart interatrial septum anatomy. Ann Anat. 2018; 217: 24-28, doi: 10.1016/j.aanat.2018.01.002, indexed in Pubmed: 29458135.

16. Ikeda U, Ohkawa F, Seino Y, et al. Serum interleukin 6 levels become elevated in acute myocardial infarction. J Mol Cell Cardiol. 1992; 24(6): 579-584, doi: 10.1016/00222828(92)91042-4, indexed in Pubmed: 1518075. 
17. Kitagawa T, Yamamoto H, Horiguchi J, et al. Characterization of noncalcified coronary plaques and identification of culprit lesions in patients with acute coronary syndrome by 64-slice computed tomography. JACC Cardiovasc Imaging. 2009; 2(2): 153-160, doi: 10.1016/j.jcmg.2008.09.015, indexed in Pubmed: 19356549.

18. Kukielka GL, Smith CW, LaRosa GJ, et al. Interleukin-8 gene induction in the myocardium after ischemia and reperfusion in vivo. J Clin Invest. 1995; 95(1): 89-103, doi: 10.1172/JCl117680, indexed in Pubmed: 7814650.

19. Lavagno L, Gunella G, Bardelli C, et al. Anti-inflammatory drugs and tumor necrosis factor-alpha production from monocytes: role of transcription factor NF-kappa B and implication for rheumatoid arthritis therapy. Eur J Pharmacol. 2004; 501(1-3): 199-208, doi: 10.1016/j. ejphar.2004.07.101, indexed in Pubmed: 15464079.

20. Lelovas PP, Kostomitsopoulos NG, Xanthos TT. A comparative anatomic and physiologic overview of the porcine heart. J Am Assoc Lab Anim Sci. 2014; 53(5): 432-438, indexed in Pubmed: 25255064.

21. Ley K, Huo Y. VCAM-1 is critical in atherosclerosis. J Clin Invest. 2001; 107(10): 1209-1210, doi: 10.1172/JCl13005, indexed in Pubmed: 11375406.

22. Libby P. The vascular biology of atherosclerosis. Chapter in book: Braunwald's Heart disease, 7Th Ed. Elsevier-Saunders, Philadeplhia 2005: 921-993.

23. Libby P, Ridker PM, Maseri A. Inflammation and atherosclerosis. Circulation. 2002; 105(9): 1135-1143, doi: 10.1161/ hc0902.104353, indexed in Pubmed: 11877368.

24. Liuzzo G, Crea F, Santamaria M, et al. Persistent activation of nuclear factor kappa-B signaling pathway in patients with unstable angina and elevated levels of C-reactive protein. J Am Coll Cardiol. 2007; 49(2): 185-194, doi: 10.1016/j.jacc.2006.07.071.

25. Marie C, Cavaillon M. Negative feedback ininflammation. The role of anti-inflammatory cytokine. Bulletin de L Institute Pasteur. 1997; 95: 141-154.

26. Martínez GJ, Robertson S, Barraclough J, et al. Colchicine acutely suppresses local cardiac production of inflammatory cytokines in patients with an acute coronary syndrome. J Am Heart Assoc. 2015; 4(8): e002128, doi: 10.1161/ JAHA.115.002128, indexed in Pubmed: 26304941.

27. Mitsumata M, Fishel RS, Nerem RM, et al. Fluid shear stress stimulates platelet-derived growth factor expression in endothelial cells. Am J Physiol. 1993; 265(1 Pt 2): H3-H8, doi: 10.1152/ajpheart.1993.265.1.H3, indexed in Pubmed: 8342646.

28. Moulton KS, Heller E, Konerding MA, et al. Angiogenesis inhibitors endostatin or TNP-470 reduce intimal neovascularization and plaque growth in apolipoprotein E-deficient mice. Circulation. 1999; 99(13): 1726-1732, doi: 10.1161/01.cir.99.13.1726, indexed in Pubmed: 10190883.

29. Mourouzis K, Oikonomou E, Siasos G, et al. Pro-inflammatory cytokines in acute coronary syndromes. Curr Pharm Des. 2020; 26(36): 4624-4647, doi: 10.2174/13816128 26666200413082353, indexed in Pubmed: 32282296.

30. Rafieian-Kopaei M, Setorki M, Doudi M, et al. Atherosclerosis: process, indicators, risk factors and new hopes. Int J Prev Med. 2014; 5(8): 927-946, indexed in Pubmed: 25489440.
31. Robertson S, Martínez GJ, Payet CA, et al. Colchicine therapy in acute coronary syndrome patients acts on caspase- 1 to suppress NLRP3 inflammasome monocyte activation. Clin Sci (Lond). 2016; 130(14): 1237-1246, doi: 10.1042/ CS20160090, indexed in Pubmed: 27129183.

32. Rong JX, Rangaswamy S, Shen L, et al. Arterial injury by cholesterol oxidation products causes endothelial dysfunction and arterial wall cholesterol accumulation. Arterioscler Thromb Vasc Biol. 1998; 18(12): 1885-1894, doi: 10.1161/01.atv.18.12.1885, indexed in Pubmed: 9848880.

33. Ross R. Atherosclerosis: an inflammatory disease. N Engl J Med. 1999; 340(2): 115-126, doi: 10.1056/ NEJM199901143400207, indexed in Pubmed: 9887164.

34. Russell DA, Abbott CR, Gough MJ. Vascular endothelial growth factor is associated with histological instability of carotid plaques. Br J Surg. 2008; 95(5): 576-581, doi: 10.1002/bjs.6100, indexed in Pubmed: 18344184.

35. Sabatine MS, Morrow DA, de Lemos JA, et al. Multimarker approach to risk stratification in non-ST elevation acute coronary syndromes: simultaneous assessment of troponin I, C-reactive protein, and B-type natriuretic peptide. Circulation. 2002; 105(15): 1760-1763, doi: 10.1161/01. cir.0000015464.18023.0a, indexed in Pubmed: 11956114.

36. Sakaguchi H, Takeya M, Suzuki H, et al. Role of macrophage scavenger receptors in diet-induced atherosclerosis in mice. Lab Invest. 1998; 78(4): 423-434, indexed in Pubmed: 9564887.

37. Sean PD. Cellular and oxidative mechanisms associated with interleukin- 6 signaling in the vasculature. Int J Mol Sci. 2017; 18(12), doi: 10.3390/ijms18122563, indexed in Pubmed: 29186034.

38. Sheth AR, Grewal US, Patel HP, et al. Possible mechanisms responsible for acute coronary events in COVID-19. Med Hypotheses. 2020; 143: 110125, doi: 10.1016/j. mehy.2020.110125, indexed in Pubmed: 32763657.

39. Spoletini M, Taurone S, Tombolini M, et al. Trophic and neurotrophic factors in human pituitary adenomas (Review). Int J Oncol. 2017; 51(4): 1014-1024, doi: 10.3892/ ijo.2017.4120, indexed in Pubmed: 28902350.

40. Taurone S, Galli F, Signore A, et al. VEGF in nuclear medicine: Clinical application in cancer and future perspectives (Review). Int J Oncol. 2016; 49(2): 437-447, doi: 10.3892/ ijo.2016.3553, indexed in Pubmed: 27277340.

41. Ueland T, Aukrust $P$, Caidahl K. CCL21 and prognosis in acute coronary syndrome. Aging. 2019; 11(21): 9225-9226, doi: 10.18632/aging. 102443.

42. Vaidya K, Martínez G, Patel S. The role of colchicine in acute coronary syndromes. Clin Ther. 2019; 41(1): 11-20, doi: 10.1016/j.clinthera.2018.07.023, indexed in Pubmed: 30185392.

43. Yang Ke, Zhang XJ, Cao LiJ, et al. Toll-like receptor 4 mediates inflammatory cytokine secretion in smooth muscle cells induced by oxidized low-density lipoprotein. PLoS One. 2014; 9(4): e95935, doi: 10.1371/journal. pone.0095935, indexed in Pubmed: 24755612.

44. Zohlnhöfer D, Richter T, Neumann FJ, et al. Transcriptome analysis reveals a role of interferon-gamma in human neointima formation. Mol Cell. 2001; 7(5): 1059-1069, doi: 10.1016/s1097-2765(01)00239-8. 